POLÍTICAS DE LA SUBJETIVIDAD URBANA. BAUDELAIRE Y BENJAMIN

Policies of the urban self. Baudelaire and Benjamin

Juan José Gómez Gutiérrez*

\title{
INTRODUCCIÓN
}

Este trabajo plantea la cuestión de la oposición ciudad/subjetividad artística a partir de las conexiones que establece Baudelaire entre actitud (artística), espacios (bohemia), identidad (dandi) y actividad (flânerie), su doble dimensión literaria y vital, desde la perspectiva de su carácter antagonista respecto de la organización tecnocráticoracional del espacio social.

El dandi se refiere a un tipo definido por la distinción personal, la belleza como ideal. La flânerie, al callejeo inteligente y ocioso, siempre dispuesto para lo extraordinario y fascinante. La bohemia, al espacio en el que se desenvuelven o construyen con su actividad. En conjunto, estos términos experimentan una dinámica histórica peculiar. Las implicaciones epistemológicas de la flânerie aparecen ya en E. A. Poe (2006). A la interpretación de Baudelaire se debe, sin embargo, la concreción en una subjetividad ociosa, forjada en la resistencia a la vulgaridad y contrapunto del trabajo asalariado. Así adquiere una dimensión política que es posible relacionar con ejemplos significativos de la literatura marxista de la segunda mitad del siglo XIX, como el propio Manifiesto comunista, o las reflexiones acerca del artista en la era del "comercio competitivo" de William Morris (2005).

Benjamin establece la relación entre conocimiento, política y subjetividad cuando sitúa al flâneur en el centro de su teoría de la urbanización. Si la ciudad es la expresión espacial del capitalismo tecnocrático, la flânerie es una estrategia de fragmentación crítico-estética del régimen económico de organización del espacio. $\mathrm{La}$ coherencia racional de la ciudad, donde cada parte es funcional al conjunto, es la forma en la que el sistema se presenta como necesario. El distanciamiento del flâneur lo muestra como contingente. Deshace el hechizo de su necesidad para presentar a la conciencia la realidad de las cosas como son, no como deben ser. Supone, mediante el movimiento aleatorio ajeno a la circulación de mercancías, al trabajo y al consumo, una crítica de la forma autorreferente que sojuzga los elementos particulares bajo una unidad fantasmagórica. Así, la flânerie se torna un platónico "salvar los fenómenos" (Benjamin, 2006, p. 229) con cariz antiideológico y liberador. Aunque Benjamin también percibió el carácter inestable del flâneur y el modo en que podría reintegrarse en nuevos ciclos de acumulación como turista, clase creativa o, en general, productorconsumidor de experiencias urbanas. 


\section{CAPITALISMO Y OCIO}

Cuando Baudelaire define el dandismo en El pintor de la vida moderna, alude a un antiguo modelo aristocrático de actitud artística y ociosa: "una institución muy antigua, puesto que César, Catilina, Alcibíades nos proporcionan brillantes ejemplos" y los autores que la han tratado "se han esforzado ante todo, muy atinadamente, de dotar a sus personajes de fortunas lo suficientemente vastas como para pagar sin vacilación todas sus fantasías", aunque no sea ni mucho menos la ocupación del dandi "aspirar al dinero como algo esencial y un gusto desmesurado por el atuendo y la elegancia material" (Baudelaire, 1995, p. 113-114).

Baudelaire reconoce su inspiración en el protagonista de un cuento de Poe, $E l$ hombre de la multitud: un personaje ocioso en Londres por la convalecencia de una enfermedad, abierto a las situaciones y estímulos que le salen al paso, con una actitud entre aburrida y curiosa, espectador del trajín callejero. Esta convalecencia toma la forma de distanciamiento de la rutina y tiempo de no negocio que pasa observando la ciudad por la ventana de un café, clasificando sujetos, grupos y actividades hasta que queda fascinado por una fisonomía inclasificable, cuya razón o relación con el conjunto necesita desentrañar.

Escribía Rubén Darío (1910) que Poe era "un caballero medieval trasplantado a un mundo de pastores protestantes, tenderos, rentistas y mercachifles" (p. 23) entre los que buscaba establecer un espacio literario autónomo, el tiempo de la convalecencia como estrategia crítica. En Baudelaire se consolida como tema poético el drama de este caballero ideal de vida artística, desdeñoso del burgués y el capital que a todos atribuye una función en el eterno reproducirse de la mercancía. El ocio del dandi se torna así en contradicción vivida entre la propia identidad y la organización tecnocrática y mercantil de su espacio vital ${ }^{1}$. Si la actividad del trabajador es funcional al proceso económico, el dandi no tiene función: "Los otros son plebeyos y jornaleros, hechos para la cuadra, es decir, para ejercer lo que se llaman las profesiones" (Baudelaire, 2009, p. 20). El dandi "no es el especialista / Es el hombre de ocio y educación general" (p. 27). Estos versos de Mi corazón al desnudo pueden ser también ilustrativos:

En parte, he crecido gracias al ocio.

En detrimento mío; porque el ocio, sin fortuna, aumenta

las deudas, las vejaciones que resultan de las deudas.

Pero, en provecho mío, en cuanto a la sensibilidad, a la

meditación y la facultad del dandismo y el diletantismo.

Los otros literatos son, en su mayoría, jornaleros demasiado ignorantes (p. 44)

\footnotetext{
${ }^{1}$ Respecto de la relación del estilo de vida de Baudelaire con el dinero, Benjamin (1972, p. 46) calcula que, con toda su obra, no ganó más de 15.000 francos, habiendo gastado, según Cussen (1986, p. 283), en torno a 65.000 de 1842 a 1844 en París. Finalmente su madre acudió a un tribunal para intervenir sus finanzas. A pesar de ello, en 1850, sus deudas ascendían a más de 21.000 francos, que se habían convertido en 40.000 en 1860.
} 


\section{EL DANDI COMO IDEAL}

En la literatura marxista contemporánea a Baudelaire se encuentran algunos análisis relevantes de crítica de la vulgaridad burguesa como contrapuesta al mundo idealizado del Antiguo Régimen que pueden ofrecer un contexto político para el ideal del dandi. Una conexión podría estar en su admiración por Joseph De Maistre y la caracterización del legitimismo francés en el Manifiesto comunista como "socialismo feudal": un tipo de anticapitalismo propio de una clase condenada a desaparecer ante la expansión de la sociedad burguesa: "mezcla de lamento, eco del pasado y rumor sordo del porvenir [...] que de vez en cuando asestaba a la burguesía un golpe en medio del corazón con sus juicios sardónicos y acerados". Lo interesante en este caso es la palabra "socialismo": la cierta identificación que Marx y Engels concedían a la distinción entre su socialismo científico y el de otros grupos sociales remanentes del Antiguo Régimen amenazados con la desposesión, pues "todas las clases sociales contribuyen a nutrir las filas del proletariado" (Marx y Engels, 2016b).

No obstante, si lo característico del proletariado es la absoluta desposesión, la negación de sí es precisamente la condición a superar hacia el ideal del individuo radical liberado mediante la toma de conciencia de la fractura entre subjetividad y condiciones materiales de su existencia. Este ideal o "rumor sordo del porvenir", como lo llama el Manifiesto, no podía ser más que imaginado a partir de modelos presentes de anticapitalismo, y aquí puede encontrarse una conexión con ese tipo de "socialismo feudal" y su desarrollo literario y vital en la irreducible individualidad del dandi, que recuerda, por ejemplo, al conocido pasaje de la Critica de Gotha:

cuando, con el desarrollo de los individuos en todos sus aspectos, crezcan también las fuerzas productivas y corran a chorro lleno los manantiales de la riqueza colectiva, solo entonces podrá rebasarse totalmente el estrecho horizonte del derecho burgués y la sociedad podrá escribir en sus banderas: ¡De cada cual, según sus capacidades; a cada cual según sus necesidades! (Marx, 2016a).

En William Morris se hacen evidentes las relaciones entre el marxismo y el ideal de liberación basado en el ocio, la belleza y el desdén por la estandarización vulgar: por la apabullante fealdad que prodigaba el capital. De hecho la forma en que Morris percibe el proceso de proletarización que describe el Manifiesto es crucial para entender su política de alianzas entre los artistas y los trabajadores. "Cualquier empleo en el que se puede hacer algo mejor o peor resulta placentero" (Morris, 2005, p. 53). Sin embargo, la organización racional de la producción aliena al ser humano en un insoportable tedio al que parecen precipitarse todos los grupos sociales: "el trabajo mecánico ha engullido al trabajo inteligente y a todo el flanco inferior del trabajo imaginativo y la enorme cantidad de lo pésimo se enfrenta ahora al escaso pero todavía brillante despliegue de lo óptimo; el arte restante se retira a su bastión del arte intelectual más elevado" (p. 57). Semejante retirada no puede conducir a otra cosa que al fin del 
arte, triturado por la mediocridad estandarizada. Y sobre esa base pretende establecer Morris un frente opositor: "somos gente digna e importante que se muere de aburrimiento [... De modo que] el amor al arte, es decir, al verdadero placer de vivir les ha llevado a esto: a tener que unir su suerte a la del esclavo asalariado... Ustedes que ansían ser liberados de la opresión de los desenterradores de dinero..." (p. 129).

El programa socialista de Morris consiste en la conquista del ocio entendido como difusión universal del arte. En concreto "¿cómo va a conseguir el pueblo en general suficiente descanso del trabajo y suficiente alivio de la ansiedad para dejar sitio a su deseo innato de belleza?" (p. 48). Conviene precisar la distinción entre ocio y tiempo libre porque este último es inseparable del trabajo asalariado: "quienes lo realizan deben abstraer su mente por completo... o deben sufrir al llevarlo a cabo un hastío tan atroz que apenas resulta imaginable". El tiempo libre consistiría pues en los momentos en los que no se están realizando estas tareas, necesario para reponer fuerzas y por tanto sometido al trabajo. El ocio, por el contrario, es tiempo de negación del negocio, de la actividad liberada o artística: "me puse a pensar en mis amigos, simples artistas, y por tanto -ya saben- gente vaga por definición. Descubrí que lo único de lo que disfrutaban era su trabajo y que su única idea de ocio feliz era otro trabajo" (p. 52).

\section{DiALÉCTICA DEL CALLEJEO}

"La burguesía somete el campo al imperio de la ciudad". Además, la urbanización no es neutral respecto de la organización social del trabajo: "aglomera la población, centraliza los medios de producción y concentra en manos de unos cuantos la propiedad" (Marx y Engels, 2016b). Con argumentos seminales, David Harvey (1975) ha sistematizado la percepción marxista de que la dinámica de acumulación capitalista genera una estructura espacial determinada por la expansión indefinida de la urbanización en forma de escisión centro-periferia en un radio constantemente ampliado. Es decir: si la contigüidad es fundamental para la optimización de la producción y circulación de mercancías, cuanto más se someta el territorio a la organización racional de la producción, mayor será el grado de urbanización y, al mismo tiempo, mayor el agudizamiento de las jerarquías socioespaciales en la relación de la ciudad con su entorno y en su propio interior. Además, la mercancía no está concluida hasta que no está en el mercado. Su circulación determina los medios de transporte y por tanto la organización física del espacio según su lógica. Aunque esta circulación supone tiempo de capital ocioso, inversamente proporcional a la tasa de beneficio. Es inherente al capitalismo, por tanto, un proceso de "compresión" en entidades metropolitanas que obedece al imperativo de la optimización de la producción fundada en la eliminación del tiempo sin propósito $^{2}$. El propio sistema implica reducir

\footnotetext{
${ }^{2}$ Alfred Marshall (1979), propone como unidad de estudio una entidad de base local-territorial entendida como centro productivo que aglomera las diversas formas de capital. Algunos años después, Frederick Taylor pone como objetivo de la administración científica del trabajo: "el enorme ahorro de tiempo y por tanto el incremento de la producción que es posible lograr eliminar movimientos innecesarios y sustituyendo movimientos lentos e 280
} 
la distancia a duración: "la anulación del espacio por el tiempo" (Marx, 2007, p. 13) mediante el management racional y la tecnología.

La estrategia del flâneur consiste en principio en preservar en el movimiento por la ciudad la individualidad ajena al trabajo instrumental y al beneficio. El incesante y preciso flujo de cosas diferentes reducidas a la condición única de mercancías da lugar a lo que Simmel llamaba actitud blasée, aburrida, hastiada o desilusionada, que es "fiel reflejo de una economía monetaria completamente internizada: al ser equivalente de todos los casos en la misma forma, el dinero se convierte en el nivelador más atroz" (Simmel, 2005, p. 4). La novedad, por su parte, es ilusión, la experiencia de lo único e irrepetible, lo efimero a punto de ser engullido por el mercado. Aunque Benjamin afirma que, en sí, lo nuevo es independiente de la mercancía. La vulgarización del espacio despierta una actitud activa en el flâneur que suspende la percepción de los objetos como mercancías para aprehenderlos como pura potencialidad: "en virtud de ese fenómeno se percibe todo aquello que solo ha sucedido aún potencialmente en el espacio" (Benjamin, 2005, p. 424) y el sujeto toma conciencia de su independencia respecto de las cosas. El flâneur es un seguidor de huellas, como el mohicano de Fenimore Cooper, o un detective, como en Poe, que domina su campo de actividad "dándose cuenta de los posibles" (P. Valèry, en Benjamin, 2005, p. 442-445). Aunque el flâneur también aparece en Benjamin como "abreviatura de la clase media en el II Imperio" (p. 425), hechizada por los pasajes comerciales; espacios donde la fascinación por la novedad misma se transforma en mercancía. Se trata en este caso de un modo vulgarizado de flâneur cuya base social es el periodismo, entendido como subordinación de la actividad intelectual a la lógica del beneficio, reorganizando la cantidad potencialmente ilimitada de acontecimientos urbanos según los intereses de la economía. El trabajo intelectual se hace así "parasitario del material" (p. 450).

Benjamin entiende las exposiciones universales y los centros comerciales como "lugares de peregrinación hacia el fetiche llamado mercancía" (p. 41) capaces de atraer al periodismo en tropel. Y la reurbanización de París -llevada a cabo por Hausmanncomo ennoblecimiento de la planificación técnica al que es inherente la escisión en centros y suburbios y la especulación. Con su definición del periodismo en concreto, Benjamin anticipa la clase creativa y el modo de desarrollo del capitalismo urbano mediante estrategias de seducción. Por otra parte, la bohemia es el producto dialéctico de la vulgarización del espacio mediante la mercantilización de la inteligencia, su contrario efimero, lo que se pone de moda y marca estilo. Aunque podría pensarse que hoy se ha convertido en la avanzadilla de la especulación urbana por su capacidad de

ineficientes por rápidos" (Taylor, 1911, p. 9. Mi traducción). Antes Simmel (2005) había definido la metrópolis como máxima expresión del modo de producción para el mercado: "Es aquí donde la multiplicidad y concentración del intercambio económico le otorgan a los medios de intercambio una importancia que el volumen de comercio rural no le hubiese permitido". Además, la concentración espacial determina la organización del tiempo: "sin la más estricta de las puntualidades. . . toda la estructura se disolvería en un caos inextricable" (Simmel, 2005, p. 2-3). 
atraer el turismo y ese tipo de trabajador cualificado, esencial en las economías contemporáneas, que migra de los aburridos páramos provincianos a entornos liberales, atractivos y fascinantes, con formas de vida estimulantes y culturalmente activas. En Benjamin, sin embargo, también designa el espacio y el tiempo de transgresión. Las tabernas y la noche, donde comparten mesa el dandi, el poeta y el revolucionario. Es el lugar de la ensoñación, el ocio irracional y la embriaguez que induce a conexiones ilógicas entre las cosas. Benjamin la caracteriza por una composición social difusa, la ambigüedad política y la inestabilidad económica. En cualquier caso, por su carácter jovialmente antiburgués y clandestino que redime las periferias.

\section{LA REVOLUCIÓN}

Si la huella que sigue el mohicano supone la "aparición de una cercanía" clara, determinada, en la que "nos hacemos con la cosa, la fantasmagoría supone la 'aparición de una lejanía' difusa, según ella 'la cosa se hace con nosotros"' (Benjamin, 2005, p. 450). Benjamin recuerda aquí la reflexión de Simmel respecto de los efectos de la ciudad, que "distancia a los hombres" racionalizándolos, evitando así la presión psicológica de demasiada cercanía entre la multitud y convirtiendo la relación entre estos en fantasmagorías: en ver las cosas como "deben ser" y no "como son" en su irreducible individualidad. El conocimiento histórico de la verdad solo es posible con la superación de la apariencia. Sin embargo, tal superación podría tornarse en fraude si implicase la volatilización del objeto, su actualización como elemento funcional a una nueva lógica. Por eso, "nada más necio que racionalizar la conducta del flâneur" (p. 426). Porque la razón suficiente por la que se despliega la lógica de la ciudad le aparece deslegitimada, como una arbitrariedad investida de aura. El fundamento primero como engaño: "el siglo no supo responder a las nuevas virtualidades técnicas con un orden social nuevo y por eso la última palabra se ha quedado en los embaucadores, trúhanes de lo antiguo y de lo nuevo, que están en el corazón de esas fantasmagorías" (p. 61).

\subsection{RACIONALIDAD Y TEOLOGÍA EN DE MAISTRE}

La política del flâneur benjaminiano consiste en deshacer el hechizo del capital sobre el espacio por la crítica, empleando la técnica del movimiento aleatorio para relativizar la organización "objetiva" de la ciudad a base de la circulación de mercancías y la acumulación indefinida. Quizá sea posible leerla a la luz de aquella afirmación de Baudelaire: "De Maistre y Edgar Poe me enseñaron a razonar" (Baudelaire, 2009, p. 65) y la conexión entre legitimismo y socialismo que establece el Manifiesto desde la crítica de la extemporaneidad del dandi ("eco del pasado, rumor sordo del porvenir...") en un mundo falsificado por el dinero.

El eje del discurso de De Maistre es el de la libertad perfecta como sumisión voluntaria a lo superior a partir de una toma de conciencia de las limitaciones humanas y la demostración, por la misma vía, de la ilegitimidad de todo poder secular no 
fundamentado en el derecho divino. Por su parte, el fundamento divino es un milagro imposible de aprehender por la razón que demuestra la acción de Dios sobre la Historia y requiere un acto consciente de sumisión. La pretensión revolucionaria de la burguesía de establecer un Estado racional es banal, pues la ciencia, que consiste en encadenamientos indefinidos de relaciones causales, no puede proporcionar un principio científico a la política que necesariamente se encuentra más allá de ella (Catoggio, 2005).

De Maistre no plantea la oposición entre fundamentos científicos o teológicos del poder, sino entre principios irracionales legítimos e ilegítimos que fundamentan el carácter coercitivo del Estado. Por ejemplo en sus Cartas sobre la Inquisición, el principio teológico es funcional al mantenimiento del poder más bien que el poder como concreción de tal principio. La Inquisición aparece como instrumento del Derecho positivo: un medio de contrarrestar el desgobierno inducido por la diversidad religiosa en España. De Maistre insiste, además, en que se trata de una institución exclusivamente política. Por ello la relación entre principio religioso y funcionalidad da lugar a un sistema autocontenido donde las partes remiten al todo y viceversa. Todo intento de fundamentarlo racionalmente conduce a su deslegitimación. Por el contrario, "todas las instituciones imaginables reposan sobre una idea religiosa o son pasajeras. Son fuertes y durables en la medida en que son divinizadas" (De Maistre, 1978, p. 16). Solo puede resistir a la crítica racional aquello fundamentado en un misterio. Y así, termina por secularizar la teología y convertirla en propaganda: "todo se reduce a la fórmula romana: Videant Consules, ne Respublica detrimentum capiat [Que los cónsules velen por la seguridad del Estado]. Por lo que hace a los medios, el mejor (aparte todo crimen) es el que consigue el objeto" (De Maistre, 1819, p. 5).

La idea de principio adquiere una dimensión central en la Revolución Francesa, donde la libertad coincide con un comienzo histórico. Sin embargo la revolución parece adquirir también en De Maistre un carácter de constante histórica y es de resaltar la afirmación de que la contrarrevolución no pretende una reforma del orden político revolucionario: "no será en absoluto una revolución contraria, sino lo contrario a la revolución" (1979, p. 54). Si, por otra parte, la revolución se funda en un principio ilegítimo violento contrario al principio "natural", podría afirmarse además que la legitimación natural del poder es también el ideal en el momento de su fundación como principio civilizatorio, un hecho milagroso, la obra de Dios. La legitimidad de los medios la confiere la violencia del Estado y la de los fines la teología.

Algo similar plantea Benjamin (2004) en su Crítica de la violencia: "el Estado teme esa violencia en su carácter de creadora de Derecho, así como debe reconocerla como creadora de Derecho allí donde fuerzas externas lo obligan a conceder el derecho" (p. 58). Esas fuerzas son la guerra y la huelga. Benjamin opone a la violencia fundadora de Derecho de la huelga política "la violencia como medio para los fines del Estado" (p. 59). Si una crea el Derecho, otra lo conserva pero ambas tienden a la preservación del Estado (p. 61-62). La secularización del Estado, su deslegitimación lo hace aparecer como violencia sin finalidad. Pero Benjamin apunta a una distinción esencial tomada de Sorel y 
su caracterización de la huelga política y la huelga proletaria. La primera es fundadora de Derecho y tiende al reforzamiento del Estado desde que busca otorgarle su finalidad. La segunda plantea su destrucción, en lugar de renegociar relaciones de poder. En este sentido no es violencia. Es pura revuelta sin teoría "que espera retomar un trabajo diferente y no impuesto" (p. 66). Si en Benjamin la revolución supone desenmascarar el carácter fantasmagórico de los fundamentos del poder, en De Maistre parece llevar implícito también este impulso purificador de lo ilegítimo.

\subsection{FANTASMAGORÍA Y LEGITIMIDAD}

La idea de "milagro" irracional como fundamento de la racionalidad histórica permite establecer una conexión con el concepto benjaminiano de fantasmagoría como principio del orden social y espacial. Es decir: De Maistre entiende la revolución y la política secular como acto satánico en el sentido teológico y de injusticia histórica. Argumentada la futilidad de su fundamento, pero su existencia en acto, la revolución no puede ser sino el brazo ejecutor del castigo divino por los pecados humanos. La percepción del castigo a los inocentes es limitada por nuestra finitud; pero el resultado final supone un bien mayor. Y, al trascurrir la historia, Robespierre, el diablo, aparece como instrumento de la voluntad de Dios: "Francia y la monarquía solo podían ser salvadas por el jacobinismo" (De Maistre, 1978, p. 25) y así, cuando Austria y Prusia amenazaban la integridad de la nación, la Convención aseguró su indivisibilidad y la regeneración del clero, abriendo paso al Directorio y al Imperio.

Respecto de la revolución como crimen e impiedad, y en calidad de seguidor político de De Maistre, "tal doble rostro de Satán le es a Baudelaire más que familiar" (De Maistre, 1978). Después de esta afirmación, Benjamin recuerda una reflexión de Marx (2016b) en el 18 Brumario de Luis Bonaparte: cuando los puritanos se quejaban en el Concilio de Constanza de la vida licenciosa de los papas, el Cardenal d'Ailli les respondía que "solo el diablo en persona puede salvar la Iglesia Católica y vosotros reclamáis ángeles". Eso mismo pensaría la burguesía francesa, según Marx, del otrora crápula y carbonario: "isolo el jefe de la sociedad del 10 de diciembre puede salvar a la sociedad burguesa! ¡Y solo el robo a la propiedad, el perjurio a la religión, los bastardos a la familia, el desorden al orden!' (citado en Benjamin, 1972, p. 36). De modo que tras el golpe de 1851 por el que Luis Bonaparte se proclama Emperador, Baudelaire al principio se irrita, pero luego mira los acontecimientos como "obra de la providencia" y "se somete como un monje" (P. Desjardins citado en Benjamin, 1972, p. 39). Hecho, en todo caso, tremendamente cínico a la luz del 18 Brumario y su concepción burlona de la repetición histórica.

A pesar de todo, en la irritación de Baudelaire por la farsa napoleónica, Benjamin (1972) percibía un "radical repudio de los poderosos [...] teocracia y comunismo no eran para él convicciones, sino susurros que se disputaban su oído" (p. 39). Entre citas del 18 Brumario (Marx, 2016b) leía al Caín de las Letanías de Satán, como "antepasado de los desheredados" y el poema en su conjunto como un canto al proletariado, una alegoría del 
materialismo histórico (p. 36): “¡Oh Satán, apiádate de mi larga miseria!/Tú que aún a los leprosos, a los parias malditos/Enseñas por amor el gusto del Paraíso". Y el Abel y Caín: "Raza de Abel, ve tus sembrados/Y tus ganados crecer/Raza de Caín, tus entrañas/Aúllan hambrientas como un viejo can". El poema termina arengando: "Raza de Caín al cielo trepa/Y sobre la tierra arroja a Dios". Y, entre bambalinas, "la tenebrosa cabeza de Blanqui" (Benjamin, 1972, p. 35): "Tú que para consolar al hombre débil que sufre/Nos enseñas a combinar el salitre y el azufre" (Baudelaire, 2016).

\section{CONCLUSIÓN}

El Satanismo de Baudelaire, sobre todo, tienta. Inicia en un saber oculto y punible que muestra a Dios como patraña y al diablo como defensor de la humanidad. Satanismo como libertad de explorar lo prohibido y abandonar la Iglesia. Aunque quizá nos parezca hoy menos perturbador que en su momento: un épater la bourgeoisie! con cierto toque de arlequinada. No así el desprecio aristocrático y revolucionario de Baudelaire por la democracia liberal y la moral burguesa del trabajo, que lo convierte en un personaje políticamente inclasificable y por ello enormemente seductor.

Esta misma inclasificabilidad a la luz de la epistemocrítica benjaminiana del flâneur, puede ayudar a poner de manifiesto algunas características de la política implícita en la subjetividad artística confrontada con la organización tecnoeconómica de la ciudad: exponer el fundamento estético (su constitución como fantasmagoría) del orden tecnocrático de la ciudad implica relativizarlo y tomar conciencia de los posibles, el momento del contenido político. Afirmar la subjetividad para sí por la vía de la negación de su funcionalidad tecnocrática y racional -de la negación de su negaciónconduce al momento de la toma de conciencia. La farsa no es mentira. Es la forma de legitimación del poder bajo las condiciones del capitalismo urbano. La crítica estética de esta forma (que consiste en su mera exposición como tal) asume por sí misma una dimensión socialmente activa.

Universidad del País Vasco / Euskal Herriko Unibertsitatea* Departamento de Filosofia de los Valores y Antropología Social Avenida de Tolosa, 7020018 Donostia, San Sebastián (España)

juanjose.gomez@ehu.eus

\section{OBRAS CITADAS}

Baudelaire, Charles (2016). Las flores del mal. Traducción de E.M.S. Danero. Santiago de Chile: Proyecto Espartaco. 01/04/2016. En: http://www.proyectoespartaco.dm.cl.

— (2009). Mi corazón al desnudo. Traducción de Jorge Segovia. Buenos Aires: Maldoror.

— (1995). El pintor de la vida moderna. Traducción de Alcira Saavedra. Murcia: Colegio Oficial de Aparejadores y Arquitectos Técnicos. 
Benjamin, Walter (2004). "Para una crítica de la violencia". Cultura Moderna № 2: 43-62.

_ (2006).“'Origen del 'Trauerspiel' barroco alemán”. Obras, Libro I/Vol. 1. Traducción de Alfredo Brotons. Madrid: Abada.

— (2005). Libro de los pasajes. Traducción de Luis Fernández Castañeda, Fernando Guerrero e Isidro Herrera Baquero. Madrid: Akal.

(1972). Iluminaciones, II. Madrid: Taurus.

Darío, Rubén (1910). "Los raros". Obras Completas, Vol. 6. Madrid: Mundo Latino.

Catoggio, María Soledad (2005). Joseph De Maistre entre la revolución y la guerra. Nómadas. Revista crítica de ciencias sociales y jurídicas $\mathrm{N}^{\mathrm{o}} 12,01 / 04 / 2016$. Disponible en: http://pendientedemigracion.ucm.es/info/nomadas/12/mscatoggio.pdf Cussen, Anthony (1986). "El poeta de la vida moderna". Estudios Públicos N $\mathrm{N}^{\mathrm{2}} 21: 281-301$. Harvey, David (1975). "The Geography of Capitalist Accumulation. A reconstruction of the Marxian Theory". Antipode Vol. 7 № 2: 9-21,

De Maistre, Joseph (1978). Estudio sobre la soberanía. Traducción de Juan Carlos Porlier. Buenos Aires: Dictio.

— (1819). Cartas a un caballero ruso sobre la Inquisición española. Traducción de N.N. Zaragoza: Francisco Magallón.

Marshall, Alfred (1979). Principles of economics, Londres: MacMillan.

Marx, Karl (2016a). Crítica del Programa de Gotha. 01/04/2016a. Disponible en: http://www.marxists.org/espanol/m-e/1870s/gotha/gotha.htm\#i

— (2016b). El 18 Brumario de Luis Bonaparte. 01/04/2016b. Disponible en: $\mathrm{http} / / /$ www.marxists.org/espanol/m-e/1850s/brumaire/brum1.htm

— (2007). Elementos fundamentales para la crítica de la economía política Vol. 1. Traducción de José Aricó, Miguel Murmis y Pedro Scarón. Madrid: Siglo XXI.

Marx, Karl y Engels, Friedrich (2016). Manifiesto del Partido Comunista. 01/04/2016. Disponible en: http://www.marxists.org/espanol/m-e/1840s/48-manif.htm

Morris, William (2005). Escritos sobre arte, diseño y política. Traducción de Juan Ignacio Guijarro. Sevilla: Doble J.

Poe, Edgar Allan (2006). "El hombre de la multitud". Bifurcaciones No 6. 01/04/2016. Disponible en: http://www.bifurcaciones.cl/006/bifurcaciones_006_reserva.pdf

Simmel, Georg (2005). “La metrópolis y la vida mental”. Bifurcaciones $\mathrm{N}^{\mathrm{0}} \overline{4} \cdot$. 01/04/2016. Disponible en: http://www.bifurcaciones.cl/004/bifurcaciones_004_reserva.pdf

Taylor, Frederick Winslow (1911). The Principles of Scientific Management, Nueva York: Harper \& Row. 